\title{
Adults with Down Syndrome: a Comprehensive Approach to Manage Complexity
}

Running title: Geriatric care for Adults with Down Syndrome

Angelo Carfi, ${ }^{1}$ Davide L Vetrano, ${ }^{1}$ Donatella Mascia, ${ }^{1}$ Eleonora Meloni, ${ }^{1}$ Emanuele R Villani, ${ }^{1}$ Nicola Acampora, ${ }^{1}$ Vincenzo Brandi, ${ }^{1}$ Brant E. Fries, ${ }^{2}$ Lynn Martin, ${ }^{3}$ Roberto Bernabei, ${ }^{1}$ Graziano Onder. ${ }^{1}$

1. Centro Medicina dell'Invecchiamento, Department of Geriatrics, Università Cattolica del Sacro Cuore, Rome, Italy

2. Department of Geriatrics and Palliative Care, Department of Internal Medicine and Department of Health, Management and Policy, School of Public Health, University of Michigan, Ann Arbor, MI, USA

3. Department of Health Sciences, Lakehead University, Thunder Bay, ON, Canada

Article text word count: 1465

Number of references: 24

Number of tables and figures: 1

\section{Authors declare no conflict of interests.}

Key words: Down syndrome, aging, comprehensive assessment

Key points:

This is the author manuscript accepted for publication and has undergone full peer review but has not been through the copyediting, typesetting, pagination and proofreading process, which may lead to differences between this version and the Version of Record. Please cite this article as doi: $10.1111 /$ jir.12588

This article is protected by copyright. All rights reserved. 
1. adults with Down syndrome present with a high level of clinical and functional complexity

2. a 'geriatric approach' based on a comprehensive assessment and management could likely deliver the highest quality care in these subjects

This article is protected by copyright. All rights reserved. 


\begin{abstract}
Background: Down syndrome (DS) is characterised by premature aging that affects selected organ systems, and persons with this condition can present patterns of comorbidities and deficits often observed in the older population without DS. However, information on the characteristics of adult persons with DS is limited.
\end{abstract}

Objective: Describe characteristics of adults with DS collected with a standardised, comprehensive assessment instrument.

Design: Cross sectional study

Setting and Subjects: 430 adults with DS (age range 18/75 years) from 3 countries (Italy, $n=95$; United States, $n=175$; Canada, $n=160$ ).

Methods: A standardised assessment instrument (interRAI Intellectual disability, or interRAI ID) was used to assess sample characteristics.

Results: Mean age ranged from 35.2 (SD 12.0) years in the US sample to 48.8 years (SD 9.0) in the Canadian sample. Most participants in the Italian and US sample were living in private homes, while more than half of those in the Canadian sample were institutionalised. Prevalences of geriatric conditions, including cognitive deficits, disability in the common activities of daily living, symptoms of withdrawal or anhedonia, aggressive behaviour, communication problems, falls and hearing problems were high in the study sample. Gastrointestinal symptoms, skin and dental problems and obesity were also frequently observed.

Conclusions: Adults with DS present with a high level of complexity, which may suggest the need for an approach based on a comprehensive assessment and management that can provide adequate care. Further research is needed to understand better the effectiveness of such an approach in the DS population.

This article is protected by copyright. All rights reserved. 


\section{Introduction}

Life expectancy of persons with Down Syndrome (DS) has progressively increased in the last century, from 9 years in 1929 to almost 60 years in 2013(Englund et al., 2013; Glasson et al., 2002; Yang et al., 2002). Such an exceptional increase has led some investigators to forecast that in a few decades persons with DS could live as long as the general population(Bittles and Glasson, 2004). Given these epidemiological changes, DS should be no longer considered a "paediatric" condition, but rather a condition that affects the whole life span. DS is considered a "segmental" progeroid syndrome, in which a premature aging affects selected organ systems, and persons with this condition might present patterns of comorbidities often observed in the older population(Carfi et al., 2017; Picciotti et al., 2017; Real de Asua et al., 2015; Schoufour et al., 2016; Vetrano et al., 2015). The clinical picture is often complicated by the presence of functional deficits, behavioural symptoms and nutritional and social problems(Carfi et al., 2014). This level of complexity requires the use of a comprehensive approach, in order to have a full understanding of the issues and needs of adults with DS(Carfi et al., 2015; Covelli et al., 2016). Such an approach is commonly adopted in geriatric medicine. The aim of the present study is understanding whether the use of a standardised comprehensive assessment tool on a sample of adults with DS from 3 countries (Italy, United States (US) and Canada) could provide useful information on their functional impairment and comorbidities.

\section{Materials and Methods}

\section{Participants}

Data on participants with DS were collected in three countries (Italy, US and Canada). Italy

Participants were adults with DS, aged 18 or older, assessed at the Day Hospital (DH) of the Geriatric Department of Policlinico A. Gemelli, Università Cattolica del Sacro Cuore in Rome. No specific inclusion criterion was required to be admitted to the $\mathrm{DH}$ except for aged 18 or older. Participants did receive a clinical assessment, following a standardised protocol, including blood sample, electrocardiogram, ophthalmologist, dentist and ear-nose-throat specialist consultation, nutrition status and body composition measurement, echocardiography, and a comprehensive assessment by the use of the InterRAI Intellectual Disability (ID) instrument. Adults with DS were directed to the DH through DS associations and from family physicians. Data on 95 adults with DS that completed clinical assessment are presented in this manuscript. 
The US data represents the full 2013 state-wide census of adults (i.e., 18+ years old) receiving intellectual/developmental disabilities services funded by the State of Arkansas Division of Developmental Disability Services, with assessments using the interRAI ID performed by trained professional assessors under contract to the state. These data include people who lived in private homes, staff homes, community residential settings, state Human Development Centers, homeless persons, and people classified as living in "other" arrangements. We report here on the 175 persons with DS in this population.

\section{Canada}

Data from Canada are based on studies of adults with intellectual or developmental disabilities living in the community and specialised institutions(Langlois and Martin, 2008). The community data comes from two separate studies, one of which focused exclusively on adults aged 50 years or more (the other study sample included adults younger than 50 years). All persons living in Ontario's institutions were assessed, so the data represent the full population; note that these specialised institutions have since closed. Assessments were collected by front-line staff who had received extensive training related to the interRAI ID. A total of 160 adults with Down syndrome were identified in the data.

InterRAI ID

Adults with DS in the study were assessed using the interRAI ID instrument, which contains over 350 data elements including socio-demographic variables, numerous clinical items about physical and cognitive status, functioning, behaviours, as well as signs, symptoms, syndromes, and treatments being provided(Martin et al., 2007). Items are completed by an assessor based on history and basic signs and symptoms (e.g. face expressions, disruptive behaviours, pain frequency and intensity, etc.) collected directly from the subject or by an informant; a number of questions are asked directly to the subject concerning his/her preferences, outlook and wellbeing. Informants are selected among the closest relatives (parents or siblings) or long standing caregivers. All assessors followed a standardised training for administration of the interRAI ID. In US and Canada data, collection was performed by trained assessors in the field of intellectual and developmental disabilities, and by trained physicians in Italy.

Clusters of items are set up in algorithms and scales to deliver clinically relevant diagnostic triggers to inform subsequent clinical evaluation; such scales have proven internally consistent and valid among 
adults with ID(Langlois and Martin, 2008; Martin et al., 2007). The cognitive performance scale (CPS) informs on current cognitive status(Morris et al., 1994). The scale scores were categorised into mild to moderate cognitive impairment (CPS scores 2 to 4 ) and severe cognitive impairment (CPS scores $\geq 5$ ). The seven point Activities of Daily Living (ADL) Hierarchy Scale informs on functioning - i.e., independence in ADLs. Score $\geq 2$ in the ADL Hierarchy Scale was used to identify participants requiring assistance in $\mathrm{ADL}$ (Morris et al., 1999). The Depression Rating Scale (DRS) was used to assess the presence of depressive symptoms with scores $\geq 3$ indicative of depression(Burrows et al., 2000). A score from 1 to 4 on the Aggressive Behaviour Scale was used to define mild/moderate aggressive behaviour and scores $\geq 5$ to define severe aggressive behaviour(Frederiksen et al., 1996). On the Social Withdrawal Scale, scores $\geq 1$ identified symptoms of withdrawal or anhedonia(Rios and Perlman, 2017). Finally, mild/moderate communication problems were defined by Communication Scale scores from 2 to 5 and severe problems by scores from 6 to 8(Frederiksen et al., 1996).

Descriptive analyses are present in this manuscript. Data were analysed using SPSS (version 18.0) for the Italian data, and SAS (Version 9.3) for the US and Canada data.

\section{Results}

Mean age of persons with DS ranged from 35.2 (SD 12.0) years in the US sample to 48.8 years (SD 9.0) in the Canadian sample (Table 1). Most participants in the Italian and US sample were living in private homes, while more than half of those in the Canadian sample were institutionalised; these differences being related to different sample recruitment and not to different social care models. Geriatric conditions occurred at high rates in the study samples, including cognitive deficits, ADL disability, symptoms of withdrawal or anhedonia, aggressive behaviour, communication problems, falls and hearing problems, while rate of urinary and faecal incontinence varied across study sites, being more commonly observed in the US and Canadian samples. Gastrointestinal symptoms, and skin and dental problems were also frequently observed, while acute conditions such as psychiatric symptoms (which includes delusions, hallucinations or abnormal thought process), dizziness and pain occurring in the three days before the assessment were uncommon. Obesity (Body Mass Index, BMI $\geq 30 \mathrm{~kg} / \mathrm{m}^{2}$ ) was also highly prevalent (BMI data not measured in Canada). Prevalence of physicians visits in the last 90 days varied across study sites ranging from $37.9 \%$ in Italy to $81.1 \%$ in the US.

This article is protected by copyright. All rights reserved. 


\section{Discussion}

We present here data on a large sample of adults with DS which demonstrate that they present with a high level of comorbidity and complexity. Despite variation in different study sites related to the enrolment procedures adopted, the data clearly show that adults with DS are characterised by presence of functional and cognitive impairments, and common occurrence of mood disorders, oral and nutritional problems, and geriatric syndromes (including anhedonia, aggressive behaviour, falls, incontinence, communication and hearing problems) - and at fairly young mean ages. This is in line with previous studies showing higher prevalences of disease with trajectories of precocious onset(Glasson et al., 2014). However, no previous study has attempted to picture the prevalence of disease and functional impairment in this population both comprehensively, i.e. with a single multidimensional instrument, and transnationally.

The approach to deliver the highest quality care to this population is still being discussed, and as a result, persons with DS resulting in complex needs may not receive appropriate care(Glasson et al., 2014). Further, adults with DS and their families often face hard times initiating the transition from paediatric to adult-based services, and the responsibility for the care of adults with DS and other congenital disabilities is poorly defined(Jensen and Davis, 2013). In the current literature, there seem to be two different approaches. Some advocate for care by general practitioners(Jensen and Bulova, 2014), though yet there remains controversy whether general practitioners are sufficiently knowledgeable, experienced, or even available to administer the proper levels of care for adults with DS(Bittles and Glasson, 2004; Henderson et al., 2007; Jensen et al., 2013). The complexity of needs of adults with DS often means that there is an increase in workload for health professionals in the primary care setting. For this reason, an approach that favours care based on comprehensive assessment and close interaction between general practitioners and management team specialised in the area of DS have been proposed(Carfi et al., 2015, 2014). This approach has been adopted and tested in geriatric medicine and it was shown to be successful independently of patient age(Ellis et al., 2011).

Comprehensive, multidimensional assessment is key to full evaluation and understanding of complexity. It provides information on the various co-morbidities, syndromes, functional and cognitive deficits experienced by adults with DS, which are not all covered by the traditional medical assessment. Comprehensive assessment, therefore, allows a more specific and sensible care plan to be developed. As presented in this study, the adoption of a comprehensive assessment instrument specifically designed for persons with intellectual disabilities (interRAI ID), might lead to better identification of problems or 
conditions associated with DS and improve diagnostic accuracy; it may also lead to initiation of needed services in a timely fashion.

Given the similarities between complex older adults in the general population and adults with DS, a 'geriatric approach' based on a comprehensive assessment and management likely represents the best intervention to optimise medical treatment, improve prognosis, restore, maintain and maximise functional autonomy, compensate for the loss of autonomy with an appropriate support, and, hopefully, improve quality of life in adults with DS. Further research is needed that examines the impact of such assessment on services and outcomes among adults with DS.

This article is protected by copyright. All rights reserved. 


\section{References}

Bittles, A.H., Glasson, E.J., 2004. Clinical, social, and ethical implications of changing life expectancy in Down syndrome. Dev. Med. Child Neurol. 46, 282-6.

Burrows, A.B., Morris, J.N., Simon, S.E., Hirdes, J.P., Phillips, C., 2000. Development of a minimum data set-based depression rating scale for use in nursing homes. Age Ageing 29, 165-72.

Carfi, A., Antocicco, M., Brandi, V., Cipriani, C., Fiore, F., Mascia, D., Settanni, S., Vetrano, D.L., Bernabei, R., Onder, G., 2014. Characteristics of Adults with Down Syndrome: Prevalence of Age-Related Conditions. Front. Med. 1. https://doi.org/10.3389/fmed.2014.00051

Carfi, A., Brandi, V., Zampino, G., Mari, D., Onder, G., 2015. Editorial: Care of adults with Down syndrome: Gaps and needs. Eur. J. Intern. Med. https://doi.org/10.1016/j.ejim.2015.04.018

Carfi, A., Liperoti, R., Fusco, D., Giovannini, S., Brandi, V., Vetrano, D.L., Meloni, E., Mascia, D., Villani, E.R., Manes Gravina, E., Bernabei, R., Onder, G., 2017. Bone mineral density in adults with Down syndrome. Osteoporos. Int. https://doi.org/10.1007/s00198-017-4133-x

Covelli, V., Raggi, A., Meucci, P., Paganelli, C., Leonardi, M., 2016. Ageing of people with Down's syndrome: a systematic literature review from 2000 to 2014. Int. J. Rehabil. Res. 39, 20-8. https://doi.org/10.1097/MRR.0000000000000147

Ellis, G., Whitehead, M.A., Robinson, D., O'Neill, D., Langhorne, P., 2011. Comprehensive geriatric assessment for older adults admitted to hospital: meta-analysis of randomised controlled trials. BMJ 343, d6553.

Englund, A., Jonsson, B., Zander, C.S., Gustafsson, J., Annerén, G., 2013. Changes in mortality and causes of death in the Swedish Down syndrome population. Am. J. Med. Genet. A 161A, 642-9. https://doi.org/10.1002/ajmg.a.35706

Frederiksen, K., Tariot, P., De Jonghe, E., 1996. Minimum Data Set Plus (MDS+) scores compared with scores from five rating scales. J. Am. Geriatr. Soc. 44, 305-9.

Glasson, E.J., Dye, D.E., Bittles, a H., 2014. The triple challenges associated with age-related comorbidities in Down syndrome. J. Intellect. Disabil. Res. 58, 393-8. https://doi.org/10.1111/jir.12026

Glasson, E.J., Sullivan, S.G., Hussain, R., Petterson, B.A., Montgomery, P.D., Bittles, A.H., 2002. The changing survival profile of people with Down's syndrome: implications for genetic counselling. Clin. Genet. 62, 390-3.

Henderson, A., Lynch, S.A., Wilkinson, S., Hunter, M., 2007. Adults with Down's syndrome: the prevalence of complications and health care in the community. Br. J. Gen. Pract. 57, 50-5.

Jensen, K.M., Bulova, P.D., 2014. Managing the care of adults with Down's syndrome. Bmj 349, g5596-g5596. https://doi.org/10.1136/bmj.g5596

Jensen, K.M., Davis, M.M., 2013. Health care in adults with Down syndrome: a longitudinal cohort study. J. Intellect. Disabil. Res. 57, 947-58. https://doi.org/10.1111/j.1365-2788.2012.01589.x

Jensen, K.M., Taylor, L.C., Davis, M.M., 2013. Primary care for adults with Down syndrome: adherence to preventive healthcare recommendations. J. Intellect. Disabil. Res. 57, 409-21. https://doi.org/10.1111/j.1365-

2788.2012.01545.x 
Langlois, L., Martin, L., 2008. Relationship between diagnostic criteria, depressive equivalents and diagnosis of depression among older adults with intellectual disability. J. Intellect. Disabil. Res. 52, 896-904.

https://doi.org/10.1111/j.1365-2788.2008.01041.x

Martin, L., Hirdes, J.P., Fries, B.E., Smith, T.F., 2007. Development and Psychometric Properties of an Assessment for Persons With Intellectual Disability?The interRAI ID. J. Policy Pract. Intellect. Disabil. 4, 23-29. https://doi.org/10.1111/j.1741-1130.2006.00094.x

Morris, J.N., Fries, B.E., Mehr, D.R., Hawes, C., Phillips, C., Mor, V., Lipsitz, L.A., 1994. MDS Cognitive Performance Scale. J. Gerontol. 49, M174-82.

Morris, J.N., Fries, B.E., Morris, S.A., 1999. Scaling ADLs within the MDS. J. Gerontol. A. Biol. Sci. Med. Sci. 54, M54653.

Picciotti, P.M., Carfi, A., Anzivino, R., Paludetti, G., Conti, G., Brandi, V., Bernabei, R., Onder, G., 2017. Audiologic Assessment in Adults With Down Syndrome. Am. J. Intellect. Dev. Disabil. 122, 333-341. https://doi.org/10.1352/1944-7558-122.4.333

Real de Asua, D., Quero, M., Moldenhauer, F., Suarez, C., 2015. Clinical profile and main comorbidities of Spanish adults with Down syndrome. Eur. J. Intern. Med. 26, 385-91. https://doi.org/10.1016/j.ejim.2015.05.003

Rios, S., Perlman, C.M., 2017. Social Withdrawal Among Individuals Receiving Psychiatric Care: Derivation of a Scale Using Routine Clinical Assessment Data to Support Screening and Outcome Measurement. J. Behav. Health Serv. Res. https://doi.org/10.1007/s11414-017-9554-y

Schoufour, J.D., Echteld, M.A., Boonstra, A., Groothuismink, Z.M.A., Evenhuis, H.M., 2016. Biochemical measures and frailty in people with intellectual disabilities. Age Ageing 45, 142-8. https://doi.org/10.1093/ageing/afv152

Vetrano, D.L., Carfi, A., Brandi, V., L’Angiocola, P.D., Di Tella, S., Cipriani, M.C., Antocicco, M., Zuccalà, G., Palmieri, V., Silveri, M.C., Bernabei, R., Onder, G., 2015. Left ventricle diastolic function and cognitive performance in adults with down syndrome. Int. J. Cardiol. https://doi.org/10.1016/j.ijcard.2015.11.041

Yang, Q., Rasmussen, S. a, Friedman, J.M., 2002. Mortality associated with Down's syndrome in the USA from 1983 to 1997: a population-based study. Lancet 359, 1019-25. https://doi.org/10.1016/S0140-6736(02)08092-3 
Table 1. Sample characteristics

\begin{tabular}{|c|c|c|c|}
\hline & Italy $(n=95)$ & United States $(n=175)$ & Canada $(n=160)$ \\
\hline \multicolumn{4}{|l|}{ Demographics } \\
\hline Age, mean \pm SD (range) & $38.1 \pm 13.3(19 / 65)$ & $35.2 \pm 12.0(18 / 62)$ & $48.8 \pm 9.0(21 / 75)$ \\
\hline Age $>40 y, n(\%)$ & $41(43.2 \%)$ & $58(33.1 \%)$ & $23(14.4 \%)$ \\
\hline Female, $\mathrm{n}(\%)$ & $47(49.5 \%)$ & 65 (37.1\%) & $62(39.2 \%)$ \\
\hline $\begin{array}{l}\text { Usual residential status } \\
\text { Private home } \\
\text { Group home } \\
\text { Institution }\end{array}$ & $\begin{array}{l}85(89.4 \%) \\
10(10.6 \%) \\
-\end{array}$ & $\begin{array}{l}146(83.5 \%) \\
12(6.9 \%) \\
17(9.7 \%)\end{array}$ & $\begin{array}{l}- \\
71(44.4 \%) \\
89(55.6 \%)\end{array}$ \\
\hline \multicolumn{4}{|l|}{ Geriatric conditions } \\
\hline $\begin{array}{l}\text { Cognitive status }^{\text {a }} \\
\text { Mild/moderate impairment } \\
\text { Severe impairment }\end{array}$ & $\begin{array}{l}60(63.2 \%) \\
14(14.7 \%)\end{array}$ & $\begin{array}{l}129(73.7 \%) \\
35(20.0 \%)\end{array}$ & $\begin{array}{l}67(41.9 \%) \\
74(46.3 \%)\end{array}$ \\
\hline Assistance required in $\mathrm{ADL}^{\mathrm{b}}$ & $27(28.4 \%)$ & $99(56.6 \%)$ & $101(63.1 \%)$ \\
\hline Depression $^{c}$ & $22(23.2 \%)$ & 85 (48.6\%) & $18(11.3 \%)$ \\
\hline Symptoms of withdrawal/anhedonia $^{\mathrm{d}}$ & $23(24.2 \%)$ & $62(35.4 \%)$ & $45(28.1 \%)$ \\
\hline $\begin{array}{l}\text { Aggressive behaviour } \\
\text { Mild/moderate } \\
\text { Severe }\end{array}$ & $\begin{array}{l}25(26.3 \%) \\
1(1.1 \%)\end{array}$ & $\begin{array}{l}81(46.3 \%) \\
16(9.1 \%)\end{array}$ & $\begin{array}{l}64(40.0 \%) \\
9(5.6 \%)\end{array}$ \\
\hline $\begin{array}{l}\text { Communication problems }{ }^{f} \\
\text { Mild/moderate impairment } \\
\text { Severe impairment }\end{array}$ & $\begin{array}{l}57(60 \%) \\
9(9.5 \%)\end{array}$ & $\begin{array}{l}98(56.0 \%) \\
63(36.0 \%)\end{array}$ & $\begin{array}{l}71(44.4 \%) \\
70(43.8 \%)\end{array}$ \\
\hline At least one fall in the last 90 days & $12(12.7 \%)$ & $30(17.1 \%)$ & $14(8.8 \%)$ \\
\hline Urinary incontinence & $7(7.4 \%)$ & $49(28.0 \%)$ & $68(42.5 \%)$ \\
\hline Faecal incontinence & $3(3.2 \%)$ & $49(28.0 \%)$ & $45(28.1 \%)$ \\
\hline Hearing problems ${ }^{\mathrm{g}}$ & $28(29.5 \%)$ & $47(26.9 \%)$ & $34(21.3 \%)$ \\
\hline \multicolumn{4}{|l|}{ Symptoms \& other conditions } \\
\hline $\begin{array}{l}\text { Pain }^{\text {h }} \\
\text { No/less than daily } \\
\text { Daily but not severe } \\
\text { Daily severe }\end{array}$ & $\begin{array}{l}82(94.3) \\
4(4.6) \\
1(1.1) \\
\end{array}$ & $\begin{array}{l}155(88.6 \%) \\
16(9.1 \%) \\
4(2.3 \%)\end{array}$ & $\begin{array}{l}148(92.5 \%) \\
10(6.3 \%) \\
1(0.6 \%)\end{array}$ \\
\hline Dizziness in the last 3 days & $5(5.3 \%)$ & $7(4.0 \%)$ & $3(1.9 \%)$ \\
\hline $\begin{array}{l}\text { Gastrointestinal symptoms in the last } 3 \\
\text { days }\end{array}$ & $38(40 \%)$ & 47 (26.9\%) & $22(17.6 \%)$ \\
\hline Psychiatric symptoms ${ }^{j}$ in the last 3 days & $5(5.3 \%)$ & $22(12.6 \%)$ & $7(4.4 \%)$ \\
\hline Skin problems ${ }^{k}$ & $28(29.5 \%)$ & $130(74.3 \%)$ & $77(49.0 \%)$ \\
\hline \multicolumn{4}{|l|}{ Nutrition } \\
\hline Dental problems & $63(66.3 \%)$ & $40(22.9 \%)$ & $26(16.4 \%)$ \\
\hline $\begin{array}{l}\text { Body mass Index }\left(\mathrm{kg} / \mathrm{m}^{2}\right)^{\mathrm{m}} \\
<18.5 \\
18-5-25 \\
25-30 \\
30 \text { or more }\end{array}$ & $\begin{array}{l}1(1.1 \%) \\
41(43.2 \%) \\
27(28.4 \%) \\
25(26.3 \%)\end{array}$ & $\begin{array}{l}3(1.7 \%) \\
34(19.4 \%) \\
44(25.1 \%) \\
94(53.7 \%)\end{array}$ & $\begin{array}{l}- \\
- \\
-\end{array}$ \\
\hline Visits and admissions (last 90 days) ${ }^{n}$ & & & \\
\hline
\end{tabular}

This article is protected by copyright. All rights reserved. 


\begin{tabular}{|l|l|l|l|}
\hline Physician visits & $36(37.9 \%)$ & $142(81.1 \%)$ & $107(66.9 \%)$ \\
\hline Inpatient acute hospital admission & $5(5.3 \%)$ & $6(3.4 \%)$ & $2(1.3 \%)$ \\
\hline Emergency room visits & $8(8.4 \%)$ & $10(5.7 \%)$ & $2(1.3 \%)$ \\
\hline Visits with mental health physician & $3(3.2 \%)$ & $27(15.4 \%)$ & $14(8.8 \%)$ \\
\hline
\end{tabular}

a. Mild/moderate cognitive impairment is defined by Cognitive Performance Scale score $2-4$, severe impairment by Cognitive Performance Scale score 5-6.

b. Assistance required is defined by ADL hierarchical scale score 2 or higher.

c. Depression Rating Scale score $\geq 3$.

d. Social Withdrawal Scale score $\geq 1$

e. Mild/moderate aggressive behaviour is defined by Aggressive Behaviour Scale score 1-4, severe aggressive behaviour by Aggressive Behaviour Scale 5 or more.

f. Mild/moderate communication problems are defined by Communication Scale score $2-5$, severe problems by Communication Scale score 6-8.

g. Defined as a difficulty to hear (with hearing appliance normally used) at least in some environments (e.g., when person speaks softly or is more than 2 metres away).

h. Person complains or shows evidence of pain (including grimacing, teeth clenching, moaning, withdrawal when touched, or other nonverbal signs suggesting pain)

i. Including acid reflux or constipation or diarrhoea or vomiting.

j. Including delusion or hallucinations or abnormal thought process.

k. Including bruises or rashes or itching or mottling or herpes zoster or intertrigo or eczema.

I. Including presence of broken, fragmented, loose, or otherwise nonintact natural teeth or gum (soft tissue) inflammation or bleeding adjacent to natural teeth or tooth fragments.

m. BMI data not collected in Canada

n. Used the specified health service at least once in the last 90 days 